\title{
Postpartum Birinci Ayda Depresyon ve Emzirme Özyeterliliği Arasındaki İlişki
}

\author{
The Relationship Between Depression and \\ Breastfeeding Self-Efficacy In The First Month of \\ Postpartum
}

(Araştırma)

Semiha Aydın Özkan*, Ayşe Merve Bozkurt", Büşra Korkmaz"***, Gizem Yılmaz****, Didem Șimșek Küçükkelepce

ÖZ

Amaç: Bu araştırma, vajinal doğum yapan kadınlarda, doğum sonrası birinci ayda depresyon ve emzirme öz yeterlilik arasındaki ilişkiyi saptamak amacıyla yapıldı.

Gereç ve Yöntem: Bu araştırma tanımlayıcı ilişki arayıcı tipte bir çalışmadır. Örneklemini postpartum 1.ayda lohusa izlemi ve yeni doğan aşısı için ASM’ye başvuran, 18 yaş üstü, gebelik öncesi ve gebelik döneminde psikiyatrik hastalığı olmayan, vajinal doğum yapan 218 kadın oluşturdu. Veriler araştırmacılar tarafından oluşturulan sosyodemografik bilgi formu, Edinburgh Doğum Sonrası Depresyon (EDSDÖ) ve Emzirme Öz-Yeterlilik Ölçeği(EÖYÖ) kullanılarak yüz yüze görüşme tekniği ile toplandı. Verilerin değerlendirilmesinde tek yönlü varyans analizi, bağımsız gruplarda $t$ testi, Postpartum depresyon ve emzirme öz yeterlilik arasındaki ilişkiyi belirlemek için Pearson korelasyon testi uygulandı.

Bulgular: Araştırmaya katılmayı kabul eden kadınların yaş ortalaması $27.38 \pm 4.49$ 'dur. Emzirme Öz-Yeterlilik puan ortalaması 47.80 $\pm 6.62(\mathrm{~min}=33, \max =62)$, Edinburgh Doğum Sonrası Depresyon puan ortalaması ise 14.94 \pm 3.31 (min=3, max=20) olarak bulundu. Araştırmamızda elde edilen bulgulara göre EÖYÖ ile EDSDÖ puan ortalamaları arasında negatif yönde yüksek düzeyde istatistiksel anlamlı ilişki saptandı $(r=-.680, \mathrm{p}<0.001)$.

Sonuç: Araştırma sonucunda depresyon puanının yüksek olduğu kadınlarda emzirme öz yeterlilik puanının düşük olduğu saptandı. Doğum sonrası dönemde aile sağlığı merkezlerinde çalışan ebe ve hemşirelerin, kadınlarda depresyonun erken dönemde tespit edilip çözümüne destek sağlayarak, kadının emzirme öz yeterliliğini desteklemesi önerilir.

Anahtar Kelimeler: Depresyon, doğum, emzirme, postpartum dönem

\section{ABSTRACT}

Aim: This study aims to identify the relationship between depression and breastfeeding self-efficacy in the first month of postpartum in women who had vaginal delivery.

Material and Methods: This study is descriptive and correlational type study. The study sample consisted of 218 women who applied to the FHC for the first month follow up visit after birth and newborn vaccination, who were aged over 18, who did not have a psychiatric disease before and during pregnancy, and who had vaginal delivery. Data were collected through the Socio-demographic Form developed by the researcher, Edinburgh Postnatal Depression Scale (EPDS), and Breastfeeding Self-Efficacy Scale (BSES). The questionnaires were administered via face-to-face interviews.

*Adıyaman Üniversitesi Sağlık Yüksekokulu Ebelik Bölümü, Adıyaman, Türkiye, E-Posta: semihaaydin44@gmail.com , Tel: $04162233003-4620$, ORCID: https://orcid.org/0000-0003-4538-0396

**Adıyaman Üniversitesi Sağlık Yüksekokulu Ebelik Bölümü, Adıyaman, Türkiye, E-Posta:, mrvbzkrt11@gmail.com, Tel: 05354115598, ORCID:https://orcid.org/00000002-3797-7929

***Adıyaman Üniversitesi Sağlık Yüksekokulu Ebelik Bölümü, Adıyaman, Türkiye, E-Posta: busrakorkmaz0102@gmail.com, Tel: 0543608020 , ORCID: https://orcid.org/0000-0001-8584-5384

***Adıyaman Üniversitesi Sağlık Yüksekokulu Ebelik Bölümü, Adıyaman, Türkiye, E-Posta: ylmzgzmz23@gmail.com, Tel: 05536416253 , ORCID: https://orcid.org/0000-0001-7035-2077

****Adıyaman Üniversitesi Sağllk Yüksekokulu Ebelik Bölümü, Adıyaman, Türkiye, E-Posta: didemkucukkelepce@gmail.com, Tel: $04162233003-4606$, ORCID: https://orcid.org/0000-0003-0001-2581

Bu çalışma 21-24 Eylül 2017 tarihinde Ankara/Türkiye'de gerçekletirilen 3. Uluslararası 4. Ulusal Ebelik Kongresinde sözel bildiri olarak sunulmuştur.

Geliş Tarihi: 02 Ocak 2018 Kabul Tarihi: 06 Aralık 2018

Atıf/Citation: Aydın Özkan S., Bozkurt AM., Korkmaz B., Yılmaz G., Şimşek Küçükkelepçe D. Postpartum Birinci Ayda Depresyon ve Emzirme Özyeterliliği Arasındaki Illişki. Hacettepe Üniversitesi Hemşirelik Fakültesi Dergisi, 2019; 6(1),28-35. DOl: 10.31125/hunhemsire.544119. 
Analysis of the data was performed using ANOVA and t-test in independent groups and Pearson correlation test was used to determine the relationship between postpartum depression and breastfeeding self-efficacy.

Results: Average age of the women who accepted to participate in the study was 27.38 \pm 4.49 . Breastfeeding Self-efficacy mean score was 47.80 $\pm 6.62(\min =33, \max =62)$ and Edinburgh Postnatal Depression Scale mean score was 14.94 \pm 3.31 $(\min =3, \max =20)$. Results indicated a highly significant, negative relationship between EPDS and BSES mean scores $(r=-$ $.680, \mathrm{p}<0.001)$.

Conclusion: Results indicated that breastfeeding self-efficacy scores were low in women who had high depression scores. Nurses and midwives who work in family health care centers are recommended to identify postpartum depression timely and support women's breastfeeding self-efficacy by helping them to solve this problem.

Keywords: Birth, breastfeeding, depression, postpartum period

\section{Giriş}

Postpartum depresyon, postpartum dönemin başında ya da postpartum döneme yayılan nonpsikotik depresif atak olarak tanımlanmaktadır ${ }^{1}$. Postpartum depresyon, doğumdan sonra annenin, bebeğin ve ailenin üzerinde negatif bir etkiye sahip olan irritabilite, suçluluk, tükenme, anksiyete, uyku bozuklukları ve somatik belirtilerle karakterizedir $^{2,3}$. Bu durum, ICD-10 (World Health International Classification of Disorders, 10th revision) ve DSM-IV (Diagnostic and Statistical Manual of Mental Disorders) tarafından resmi bir tanı olarak kabul edilmiştir. ICD-10 postpartum depresyonu tanılamak için en kritik dönemin doğumdan itibaren 6 hafta içinde olduğunu belirtirken ${ }^{4}$, DSM-IV doğum sonrası 4 hafta içinde postpartum depresyon atağının başlayabileceğini belirtmektedir 5 . Doğumdan sonraki bir yıl postpartum depresyon için yüksek risk dönemi olarak kabul edilmektedir ${ }^{6}$. Postpartum depresyon anne-bebek bağlanmasını ciddi bir şekilde etkilemekte, annenin, bebeğin ve ailenin çeşitli güçlükler yaşamasına neden olmakta, annenin bebek bakımını öğrenmesini ve ebeveynlik rolüne geçişini olumsuz etkilemektedir ${ }^{7}$. Doğum sonu depresyon deneyimleyen anneler kendilerini kaybolmuş, bebeklerinin sorumluluğunu alma konusunda güçsüz olarak görmekte ve bu anneler emzirme sorunları ve kaygıları ile savaşmaktadır ${ }^{10}$.

Emzirme, hem çocuğa hem de anneye çok çeşitli avantajlar sunan bir besleme yöntemidir ${ }^{8}$. Emzirme öz-yeterlilik algısı ise annenin emzirip emziremeyeceğini, emzirmek için ne kadar gayret göstereceğini, emzirmeyle ilgili düşüncelerini ve duygusal olarak emzirirken oluşabilecek zorluklar ile başa çıkabilmesi olarak tanımlanmaktadır . Annenin bebeğine sağlıklı bir şekilde bakabilmesi ve emzirme problemleri yaşamaması için öncelikle kendi beden ve ruh sağlı̆̆ının yerinde olması gerekir 6 .

Literatür incelendiğinde postpartum dönemin farklı zamanlarında ve farklı ölçekler kullanılarak, postpartum depresyon ve emzirme arasındaki ilişkiyi saptamaya çalışan pek çok çalışma tespit edilmiştir. Bazı çalışmalarda postpartum depresyonla emzirme arasında ilişki olmadığı belirtilmiştir ${ }^{10-13}$. Ancak emzirmenin, postpartum depresyon tedavisi için önemli bir konu olduğu ve emzirmeyi bırakmanın oluşturduğu sosyal baskı ve suçluluk duygusunun başlı başına ek bir stresör haline geleceği söylenmiştir ${ }^{14}$. Bazı çalışmalarda da postpartum depresyon deneyimleyen annelerin emzirmeyi bıraktıkları, emzirme öz-yeterliliklerinin düşük olduğu, kendilerine güvenmedikleri, emzirme sürecinin olumsuz etkilendiği belirtilmiştir ${ }^{15-17}$.

$\mathrm{Bu}$ nedenle emzirme konusunda olumsuz sonuçları azaltmak için doğum sonu bakım veren hemşirelerin depresyondaki anneyi tanımak ve tedavi etmek için risk taramaları yapmaları oldukça önemlidir.

Amaç: Vajinal doğum yapan kadınlarda, doğum sonrası birinci ayda depresyon ve emzirme öz yeterlilik arasındaki ilişkiyi saptamaktır.

\section{GEREÇ ve YÖNTEM}

\section{Araştırma Türü}

$\mathrm{Bu}$ araştırma tanımlayıı ilişki arayıcı tipte bir çalışmadır. 


\section{Araştırma Evreni ve Örneklemi}

Araştırmanın evrenini Güneydoğuda bir il merkezinde bulunan 16 Aile Sağlığı Merkezinden basit rastgele yöntemle belirlenen 2 ASM'ye kayıtlı lohusalar oluşturdu. Örneklemi ise postpartum birinci ayda lohusa izlemi ve yeni doğan aşısı için, ASM'ye başvuran 18 yaş üstü, gebelik öncesi ve gebelik döneminde psikiyatrik hastalığı olmayan, vajinal doğum yapan kadınlar oluşturdu. Araştırmanın örneklem hesabı Gpower 3.1.9 programı ile hesaplandı. Araştırmanın örneklemi hesaplanırken ilk önce etki büyüklüğü saptandı. Etki büyüklüğü, Zubaran ve ark. ${ }^{17}$ yaptığı çalışmadaki EDSDÖ ve EÖYÖ puan ortalama ve standart sapmaları alınarak hesaplandığında 0.222 olarak bulundu. Araştırmada $\% 5$ hata payı, \%95 güven aralığı ve \% 80 güç ile hesaplandığında araştırmanın örneklemini 218 lohusa kadının oluşturduğu saptandı.

\section{Veri Toplama Araçları}

Veriler, araştırmacılar tarafından oluşturulan "Tanımlayıcı Bilgi Formu”, "Edinburgh Doğum Sonrası Depresyon Ölçeği (EDSDÖ)" ve "Emzirme Öz-Yeterlilik Ölç̧ği (EÖYÖ)" kullanılarak yüz yüze görüşme tekniği ile toplandı.

\section{Tanımlayıcı Bilgi Formu}

Postpartum dönemdeki kadınların sosyo-demografik özelliklerini, obstetrik öykülerini içeren sorulardan oluşturuldu.

\section{Edinburgh Doğum Sonrası Depresyon Ölçeği}

Cox ve arkadaşları tarafından geliştirilen ölçek doğum sonrası dönemde depresyon yönünden riski belirlemek, düzey ve şiddet değişimini ölçmek için kullanılmaktadır. EDSDÖ 10 maddeden oluşan, dörtlü likert biçiminde kendini değerlendirme ölçeğidir. Dört seçenekten oluşan yanıtlar 0-3 arasında puanlanmakta, ölçekten alınabilecek en düşük puan 0 ve en yüksek puan 30'dur. Değerlendirmede 3, 5, 6, 7, 8, 9 ve 10. maddeler 3, 2, 1, 0 şeklinde ters olarak puanlanmaktadır. EDSDÖ’nün Türkçe uyarlaması Engindeniz ve arkadaşları tarafından yapılmıştır. Kesme noktası 13 olarak hesaplanmış olup, toplam ölçek puanı kesme noktasından fazla olan kadınlar risk grubu olarak kabul edilmektedir. Ölçeğin geçerlilik güvenirlik analizinde cronbach alfa değeri 0.79 olarak bulunmuştur. Bu çalışmada cronbach alfa değeri 0.75 olarak saptanmıștı1 ${ }^{18,19}$.

\section{Emzirme Öz-Yeterlilik Ölçeği}

2003 yllında Dennis tarafından oluşturulmuştur. Ölçek emzirme öz-yeterliliğini değerlendirilen toplam 14 maddeden oluşmuştur. Ölçek 5'li Likert tipinde olup, ölçeğin maddeleri 1 = "hiç emin değilim"den $5=$ "her zaman eminim"e kadar derecelendirilerek değerlendirilmektedir. Ölçekten alınabilecek en yüksek puan 70 , en düşük puan 14'dür. Kesme noktası olmayan ölçekte, puanın artması yüksek emzirme-öz yeterliliği olduğunu ifade etmektedir. Tokat, Okumuş ve Dennis tarafından Emzirme Öz-Yeterlilik Ölçeğinin kısa şeklinin Türkçe güvenirlik geçerlilik çalışması yapılmış ve Cronbach alpha değerini 0.86 bularak ölçeğin Türk kültürü için uygun olduğu saptanmıştır. Bu çalışmada cronbach alfa değeri 0.88 olarak bulunmuştur ${ }^{20,21}$.

\section{Verilerin Değerlendirilmesi}

Veriler, EDSDÖ ve EÖYÖ’nin normal dağılım gösterdiği saptandıktan sonra ortalama, standart sapma, sayı, yüzdelik hesaplamaları, tek yönlü varyans analizi, bağımsız gruplarda student $t$ testi ile değerlendirildi. Farkı yaratan grupları belirlemek için Post hoc teslerden, LSD ve Tukey testleri uygulandı. Postpartum depresyon ve emzirme öz yeterlilik arasındaki ilişkiyi belirlemek için pearson korelasyon testi kullanıldı.

\section{Araştırmanın Etik Yönü}

Araştırmanın yapılabilmesi için Adıyaman Üniversitesi Girişimsel Olmayan Klinik Araştırmalar Etik Kurulu'ndan etik kurul onayı alındı (Karar sayısı 2017/1-12). Daha sonra Halk sağlığı müdürlüğünden yazılı izin ve bütün katılımcılardan çalışmaya katılmaya gönüllü olduklarına dair sözel onam alındı.

\section{BULGULAR}

Vajinal doğum yapan kadınlarda, doğum sonrası birinci ayda depresyon ve emzirme öz yeterlilik arasındaki ilişkiyi saptamak amacıyla yapılan çalışmadan elde edilen bulgular tablolarla verildi. 
Tablo 1. Katılımcıların Tanıtıcı Özelliklerinin Dağılımı (n=218)

\begin{tabular}{|c|c|c|c|}
\hline Demografik Özellikler & & $\mathbf{n}$ & $\%$ \\
\hline \multirow[t]{3}{*}{ Yaş } & $19-24$ yas & 47 & 21.6 \\
\hline & $20-29$ yas & 110 & 50.5 \\
\hline & 30 ve üstü yas & 61 & 28.0 \\
\hline \multirow[t]{3}{*}{ Eğitim durumu } & illköğretim & 56 & 25.7 \\
\hline & Ortaöğretim & 118 & 54.1 \\
\hline & Yükseköğretim & 44 & 20.2 \\
\hline \multirow[t]{3}{*}{ Eşin eğitim durumu } & İlköğretim & 12 & 5.5 \\
\hline & Ortaöğretim & 144 & 66.1 \\
\hline & Yükseköğretim & 62 & 28.4 \\
\hline \multirow[t]{2}{*}{ Çalışma durumu } & Çalışmıyor & 135 & 61.9 \\
\hline & Çalışıyor & 83 & 38.1 \\
\hline \multirow[t]{2}{*}{ Eşin çalışma durumu } & Çalışıyor & 206 & 94.5 \\
\hline & Çalışmıyor & 12 & 5.5 \\
\hline \multirow[t]{2}{*}{ Aile tipi } & Çekirdek aile & 187 & 85.8 \\
\hline & Geniş aile & 31 & 14.2 \\
\hline \multirow[t]{4}{*}{ Gebelik sayısı } & 1 & 62 & 28.4 \\
\hline & 2 & 112 & 51.4 \\
\hline & 3 & 38 & 17.4 \\
\hline & 4 & 6 & 2.8 \\
\hline \multirow[t]{2}{*}{ Bebeğin cinsiyeti } & $\mathrm{KIz}$ & 133 & 61.0 \\
\hline & Erkek & 85 & 39.0 \\
\hline \multirow[t]{3}{*}{ Bebeğin bakımında destek alma } & Var & 78 & 35.8 \\
\hline & Yok & 140 & 64.2 \\
\hline & Total & 218 & 100.0 \\
\hline
\end{tabular}

Araştırmada katılımcıların yaş ortalaması $27.38 \pm 4.49$ (min:19, maks:45) olarak belirlendi. Katılımcıların \%50.5'inin 20-29 yaş grubunda, \%54.1'inin ortaöğretim mezunu, \%61.9'unun çalışmadığı, \%85.8'inin çekirdek ailede yaşadığı saptandı. Araştırma kapsamına alınan annelerin \%71.6'sının 2 ve üzeri yaşayan çocuğa sahip olduğu, \%61.0’ının bu doğumundaki bebeğinin kız olduğu ve \%64.2'sinin kendisine bebeğinin bakımında yardımcı olacak kimsenin olmadığı saptandı (Tablo 1).

Tablo 2. Katılımcıların EDSDÖ ve EÖYÖ Puan Ortalamalarının Dağılımı

\begin{tabular}{lccccc}
\hline Ölçekler & $\mathrm{n}$ & Ortalama & Standart Sapma & Minimum & Maksimum \\
\hline EDSDÖ & 218 & 14.94 & 3.31 & 3.00 & 20.00 \\
\hline EÖŸ̈ & 218 & 47.80 & 6.62 & 33.00 & 62.00 \\
\hline
\end{tabular}

Katılımcıların EDSDÖ ve EÖYÖ puanlarına bakıldığında EDSDÖ ve EÖYÖ puan ortalamalarının sırasıyla

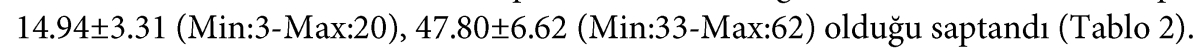

Tablo 3. Katılımcıların EDSDÖ ve EÖYÖ Puan Ortalamaları Arasındaki İlişki

\begin{tabular}{cccc}
\hline Ölçekler & & EÖYÖ & \\
& & & \\
\hline EDSDÖ & $\mathrm{n}$ & $\mathrm{r}$ & $\mathrm{p}$ \\
& 128 & -.68 & $<.001$ \\
\cline { 2 - 4 } & & & \\
\hline
\end{tabular}


Araştırmadan elde edilen bulgulara göre EDSDÖ ve EÖYÖ puan ortalamaları arasında negatif yönde ileri düzeyde ilişki olduğu ( $r=-.68$ p=.001) saptandı (Tablo 3 ).

Tablo 4. Katılımcıların tanıtıcı özelliklerine göre doğum sonu birinci ayda EDSDÖ ve EÖYÖ puan ortalamalarının dağılımı

\begin{tabular}{|c|c|c|c|c|c|c|c|}
\hline \multirow[t]{2}{*}{ Tanıtıcı Özellikler } & & \multicolumn{3}{|c|}{$\begin{array}{c}\text { Edinburgh Doğum Sonrası } \\
\text { Depresyon }\end{array}$} & \multicolumn{3}{|c|}{ Emzirme Öz-Yeterlilik } \\
\hline & & $\mathrm{X} \pm \mathrm{SD}$ & Min-Maks & İstatistik & $\mathrm{X} \pm \mathrm{SD}$ & Min-Maks & İstatistik \\
\hline \multirow[t]{3}{*}{ Yaş grubu } & $19-24$ yas & $15.31 \pm 4.53$ & $3-20$ & \multirow{3}{*}{$\begin{array}{l}F=5.368 \\
p=.005\end{array}$} & $* 41.68 \pm 5.80$ & $33-54$ & \multirow{3}{*}{$\begin{array}{c}F=36.320 \\
p<.001\end{array}$} \\
\hline & 25-29 yas & $15.41 \pm 2.61$ & $9-20$ & & $48.79 \pm 5.16$ & $43-61$ & \\
\hline & 30 ve üstü yas & $* 13.79 \pm 3.10$ & $8-17$ & & $50.77 \pm 6.66$ & $44-62$ & \\
\hline \multirow[t]{3}{*}{ Eğitim durumu } & İlköğretim & $13.54 \pm 4.21$ & $3-19$ & \multirow{3}{*}{$\begin{array}{c}F=13.985 \\
\mathbf{p}<.001\end{array}$} & $48.75 \pm 8.97$ & $36-61$ & \multirow{3}{*}{$\begin{array}{l}F=3.167 \\
p=.044\end{array}$} \\
\hline & Ortaöğretim & $14.89 \pm 3.03$ & $7-20$ & & $48.16 \pm 6.17$ & $33-62$ & \\
\hline & Yükseköğretim & *16.86 \pm 1.09 & $15-19$ & & $* 45.63 \pm 2.83$ & $42-52$ & \\
\hline \multirow{3}{*}{$\begin{array}{l}\text { Eşin eğitim } \\
\text { durumu }\end{array}$} & İlköğretim & $10.75 \pm 5.40$ & $3-16$ & \multirow{3}{*}{$\begin{array}{c}F=19.307 \\
\mathbf{p}<.001\end{array}$} & $49.17 \pm 4.39$ & $45-55$ & \multirow{3}{*}{$\begin{array}{l}F=4.662 \\
p=.010\end{array}$} \\
\hline & Ortaöğretim & $14.65 \pm 3.31$ & $7-20$ & & $48.60 \pm 7.63$ & $33-62$ & \\
\hline & Yükseköğretim & ${ }^{*} 16.44 \pm 1.42$ & $14-19$ & & $* 45.67 \pm 3.04$ & $40-52$ & \\
\hline \multirow[t]{2}{*}{ Çalışma durumu } & Çalışmıyor & $14.49 \pm 3.76$ & $3-20$ & \multirow{2}{*}{$\begin{array}{l}t=-2.559 \\
p=.011\end{array}$} & $48.23 \pm 7.97$ & $33-62$ & \multirow{2}{*}{$\begin{array}{l}t=1.216 \\
p=.225\end{array}$} \\
\hline & Çalışıyor & $15.66 \pm 2.24$ & $7-19$ & & $47.11 \pm 3.36$ & $42-54$ & \\
\hline \multirow[t]{2}{*}{ Aile tipi } & Çekirdek aile & $15.16 \pm 2.93$ & $3-20$ & \multirow{2}{*}{$\begin{array}{l}t=2.387 \\
p=.018\end{array}$} & $47.72 \pm 5.75$ & $36-62$ & \multirow{2}{*}{$\begin{array}{l}t=-0.442 \\
p=.659\end{array}$} \\
\hline & Geniş aile & $13.64 \pm 4.88$ & $7-20$ & & $48.29 \pm 10.57$ & $33-62$ & \\
\hline \multirow[t]{4}{*}{ Gebelik sayısı } & 1 & $16.11 \pm 3.60$ & $3-20$ & \multirow{4}{*}{$\begin{array}{l}F=5.510 \\
p=.001\end{array}$} & $* 43.95 \pm 6.83$ & 33-59 & \multirow{4}{*}{$\begin{array}{c}F=11.711 \\
\mathbf{p}<.001\end{array}$} \\
\hline & 2 & $* 14.13 \pm 3.36$ & $7-20$ & & $49.69 \pm 6.03$ & $43-62$ & \\
\hline & 3 & $15.26 \pm 2.04$ & $10-17$ & & $48.31 \pm 5.52$ & $44-62$ & \\
\hline & 4 & $16.00 \pm 1.10$ & $15-17$ & & $49.00 \pm 5.48$ & $44-54$ & \\
\hline \multirow{2}{*}{$\begin{array}{l}\text { Bebeğin } \\
\text { bakımında destek } \\
\text { alma }\end{array}$} & Var & $13.49 \pm 4.83$ & $3-20$ & \multirow{2}{*}{$\begin{array}{l}t=-4.026 \\
p<.001\end{array}$} & $49.67 \pm 8.31$ & $33-62$ & \multirow{2}{*}{$\begin{array}{l}t=3.169 \\
p=.006\end{array}$} \\
\hline & Yok & $15.75 \pm 1.52$ & $11-20$ & & $46.76 \pm 5.20$ & $36-62$ & \\
\hline
\end{tabular}

Tablo 4'te katılımcıların tanıtıcı özellikleri ile doğum sonu birinci ayda EDSDÖ ve EÖYÖ puan ortalamalarının karşılaştırılması verildi. Kadınları yaş grubu, eğitim durumu, çalışma durumu, aile tipi, gebelik sayısı ve bebeğin bakımında destek alma ve kadınların eşlerinin eğitim durumuna göre EDSDÖ puan ortalaması arasında istatistiksel anlamlı fark saptandı $(\mathrm{p}<.05)$. Yapılan analizlerde 30 ve üstü yaş grubu kadınlarda, çalışmayan kadınlarda, geniş ailede yaşayan kadınlarda, 2 doğum yapan kadınlarda ve bebeğin bakımında destek alan kadınlarda depresyon puan ortalamasının diğer gruplardan daha düşük olduğu saptandı ( $\mathrm{p}<.05)$. Kendisi ve eşi yükseköğretim mezunu olan kadınlarda da depresyon puan ortalamasının daha yüksek olduğu saptandı $(\mathrm{p}<.05)$.

Kadınların yaş grubu, eğitim durumu, eşlerinin eğitim durumu gebelik sayısı ve bebeğin bakımında destek alma ile EÖYÖ puan ortalaması arasında istatistiksel anlamlı fark saptandı $(\mathrm{p}<.05)$. Yapılan analizlerde 19-24 yas grubu kadınlarda, kendisi ve eşi yükseköğretim mezunu olan kadınlarda, bir doğum yapan kadınlarda ve bebeğin bakımında destek almayan kadınlarda emzirme özyeterlilik puan ortalamalarının diğer gruplardan daha düşük olduğu saptand1 $(\mathrm{p}<.05)$.

Tablo 5. Postpartum depresyon olan ve olmayan kadınlarda emzirme öz yeterlilik puan ortalaması dağılımı

Emzirme Öz Yeterlilik Puan Ortalaması

\begin{tabular}{|c|c|c|}
\hline Depresyon Yok & Depresyon Var* & Istatistik \\
\hline $57,36 \pm 5,09$ & $45,91 \pm 5,07$ & $\begin{array}{c}\mathrm{t}=12,370 \\
\mathrm{P}<0,001\end{array}$ \\
\hline
\end{tabular}

${ }^{*}$ Depresyon var $\geq 13$ 
Edinburg Doğum Sonu Depresyon Ölçeğine göre depresyon deneyimleyen kadınlarda Emzirme öz yeterlilik puan ortalamasının istatistiksel anlamlı olarak daha düşük olduğu saptandı ( $\mathrm{p}<.05)$ (Tablo 5.).

\section{TARTIŞMA}

Postpartum depresyon (PPD), DSM-IV'de "Duygu Durum Bozuklukları" içinde yer almakta ve postpartum dört hafta içinde epizotun başlaması şeklinde tanımlanmaktadır ${ }^{5}$. Bu çalışmada katılımcıların EDSDÖ puanı 14.94 +3.31 olduğu saptandı. Literatüre bakıldığında Suudi Arabistan'da postpartum 2. ayda 137 kadın ile yapılan bir çalışmada EDSDÖ $9.1 \pm 6.0$ olarak belirtilmiştir ${ }^{22}$. Benzer şekilde postpartum 6 . haftada 377 kadına mail gönderilerek yapılan çalışmada EDSDÖ puan ortalamalarının $9.8 \pm 1.6$ olduğu belirtilmiştir ${ }^{23}$. Brezilya'da doğum sonrası 2. ve 12. haftalar arasında 89 annenin evlerinde ziyaret edilerek yapılan bir çalışmada EDSDÖ puan ortalaması 8.21 \pm 5.5 olarak belirtilmiştir ${ }^{17}$. Bu çalışmada postpartum dönemde depresyon tanılamaya yönelik yapılan çalışmalara göre EDSDÖ puanının yüksek olması postpartum dönemin farklı zamanlarında yapılmasına bağlı olduğunu söyleyebiliriz. Ancak postpartum dönemin hangi evresinde olursa olsun depresyon, sadece anne için değil, bebek ve tüm aile için olumsuz sonuçlar doğurabileceğinden özel bir yaklaşım gerektirmektedir ${ }^{7,24}$.

Dennis' e göre Emzirme öz-yeterlilik algısı annenin emzirmeyle ilişkin hissettiği yeterliliktir. Annenin kendi kendine edindiği emzirmede yeterlilik durumu; annenin emzirmeyi seçip seçmemesine, emzirme yöntemlerini bilip bilmemesine, bunun için ne kadar süre harcayacağına ve emzirmedeki zorluklara duygusal olarak nasıl cevap vereceğine bağlıdır ${ }^{24,25}$. Bu çalışmada katılımcıların EÖYÖ puan ortalamasının $47.80 \pm 6.62$ olduğu

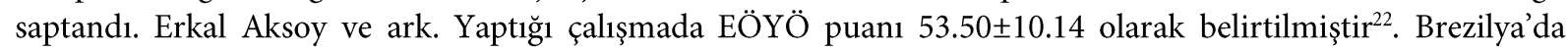
yapılan bir çalışmada doğum sonrası 2. ve 12. haftalar arasında EÖYÖ puanı $63.51 \pm 6.25$ olarak belirtilmiştir. Tokat, Okumuş ve Dennis tarafından Türkçe güvenirlik geçerlilik çalışması yapılan ölçeğin kesme puanı bulunmamakla birlikte ölçek 14-70 arasında puanlanmaktadır. Ölçek puanın artması yüksek emzirme-öz yeterliliği olduğunu ifade etmektedir ${ }^{20,21}$. Bu çalışmada EÖYÖ puanı orta düzeyde olmasına rağmen diğer çalışmalara göre daha düşük olduğu görülmektedir. Bu açıdan emzirme öz yeterlilik durumunu etkileyen diğer etmenlerin değerlendirilmesi önemlidir.

Postpartum dönemde deneyimlenen depresyonun, emzirme durumu ile ilişkisi birçok araştırmada incelenmiştir. Bebeğin beslenme şeklinin annenin depresyona girmesi için bir risk olup olmadığı, ayrıca annenin duygu durumunun bebek beslenmesine etkisi çeşitli çalışmalarda araştırılmıştır ${ }^{12,13,15-17,22,23}$. Bu çalışma EDSDÖ’ye göre depresyon deneyimleyen kadınlarda EÖYÖ puan ortalamasının istatistiksel anlamlı olarak daha düşük olduğu saptandı $(\mathrm{t}=12.370 \mathrm{p}=0.001)$. Yapılan bazı çalışmalarda depresyon deneyimleyen annelerde emzirme durumu etkilenmezken ${ }^{10-13,23}$, bazılarında depresyon deneyimleyen annelerde emzirme durumunun negatif etkilendiği, annelerin emzirme konusunda kendilerine daha az güven duydukları belirtilmiştir ${ }^{17,22}$. Blyth ve ark. (2002) çalışmasında, postpartum depresyon durumunda annelerin emzirirken kendilerini yeterli görmedikleri ve kendilerine güvenmedikleri, emzirme sürecinin ve etkinliğinin olumsuz yönde etkilendiği belirtmişlerdir ${ }^{15}$. Dennis ve McQueen çalışmasında (2007) postpartum dördüncü ve sekizinci haftalarda Edinburg depresyon ölçeğinden 12'nin üstünde puan alan annelerin emzirmeyi bıraktıkları, emzirme öz-yeterliliklerinin düşük olduğunu, bebeklerini besleme konusunda daha fazla sorun yaşadıklarını belirtmişlerdir ${ }^{16}$.

Bu çalışmada 30 ve üstü yaş grubu kadınlarda, çalışmayan kadınlarda, geniş ailede yaşayan kadınlarda, 2 doğum yapan kadınlarda ve bebeğin bakımında destek alan kadınlarda EDSDÖ puan ortalamasının diğer gruplardan daha düşük olduğu saptandı $(\mathrm{p}<.05)$. Kendisi ve eşi yükseköğretim mezunu olan kadınlarda EDSDÖ puan ortalamasının daha yüksek olduğu saptandı ( $\mathrm{p}<.05)$. EÖYÖ puan ortalamasının 19-24 yas grubu kadınlarda, kendisi ve eşi yükseköğretim mezunu olan kadınlarda, bir doğum yapan kadınlarda ve bebeğin bakımında destek almayan kadınlarda daha düşük olduğu saptandı $(\mathrm{p}<.05)$. Literatür incelendiğinde bu çalışmaya benzer şekilde doğum sonu dönemde deneyimlenen depresyonu ve emzire öz yeterliliğini etkileyen birçok faktörün olduğu görülmektedir ${ }^{12,17,22,23,27-29}$. Emzirme, anne ve bebek için oldukça yararlı bir uygulamadır. Emzirme öz yeterliliğin desteklenmesinde hemşirenin anneye fiziksel yardımının yanında cesaretlendirici rolü de önem kazanır. Emzirmenin korunması, özendirilmesi ve desteklenmesi için emzirme durumunu etkileyen faktörlerin hemşireler tarafından bilinmesi müdahale edilebilecek faktörlerin iyileştirilmesi önemli sağlık hedefleri arasında yer almalidır. 


\section{SONUÇ}

Araştırma sonucunda EDSDÖ’ye göre depresyon deneyimleyen kadınlarda EÖYÖ puanının düşük olduğu ve istatistiksel olarak aralarında ileri düzeyde anlamlı ilişki olduğu saptandı. Özellikle aile sağlı̆̆ı merkezlerinde, hemşirelerin, emzirme konusunda olumsuz sonuçları azaltmak için depresyondaki anneyi erken dönemde tespit edip çözümüne destek sağlaması oldukça önemlidir.

\section{Sonuçların Uygulamada Kullanımı}

Postpartum dönemde annenin bebeğine sağlıklı bir şekilde bakabilmesi ve emzirme problemleri yaşamaması için olumlu emzirme öz-yeterlilik algısına sahip olmaları önemlidir. Bu nedenle ASM'lerde ve hastanelerde gebe izlemi yapan hemşirelerin, risk grubunda bulunan gebelerde postpartum depresyon gelişimini etkileyen faktörlerin antenatal dönemden itibaren tanılayıp takip ederek birincil koruma önlemleri açısından ele almalıdır. Postpartum ilk bir ay annelerin depresyon deneyimlemesi kadar emzirme öz-yeterliliğinin geliştirilmesi için de kritik bir zamandır. Bundan dolayı annenin duygu durumunu ve yeni doğanın emmesini takip etmek için ebelerin ve hemşirelerin özellikle postpartum birinci haftadan sonra annelere destek sağlamalı, izlemleri geç dönemde de devam ettirmelidir.

\section{KAYNAKLAR}

1. Cox J, Murray D, Chapman G. A controlled study of the onset, duration and prevalence of postnatal depression. Br J Psychiatry.1993;163:27-31.

2. Green JM, Coupland VA, Kitzinger JV. Expectations, experiences and psychological outcomes of childbirth: a prospective study of 825 women. Birth.1990;171(1):15-24.

3. McMahon CA, Barnett B, Kowalenko NM, Tennant CC. Maternal attachment state of mind moderates the impact of postnatal depression on infant attachment. J Child Psychol Psychiatry. 2006;47(7):660-669.

4. Çuhadaroğlu F, Kaplan İ, Özgen G, Öztürk MO, Rezaki M. Dünya Sağlık Örgütü ICD-10 Ruhsal ve davranışsal bozukluklar sınıflandırması. Uluğ B (Çev.Ed). Türkiye Sinir ve Ruh Sağlığı Derneği Yayını Ankara, 1993;184-87.

5. Köroğlu E (çeviren) Amerikan Psikiyatri Birliği: Psikiyatride hastalıkların tanımlanması ve sınıflandırılması el kitabı, yeniden gözden geçirilmiş dördüncü baskı (DSM-IV-TR). Ankara:Hekimler Yayın Birliği; 2001,152-53.

6. Annagür BB, Annagür A. Doğum sonrası ruhsal durumun emzirme ile ilişkisi. Psikiyatride Güncel Yaklaşımlar.2012; 4(3):279-92.

7. Uzel N, Özbalcı S. (Çev.Ed.) 4. Bölüm Bağlanmaya zarar veren etmenler. Bağlanma. İçinde Doğum öncesi ve sonrası dönemde bağlanmanın güçlendirilmesi. Ankara: Modern Tıp Kitap Evi;2017,pp.52-54.

8. Dias CC, Figueiredo B. Breastfeeding and depression: a systematic review of the literature. J Affect Disord. 2015 Jan 15;171:142-54. doi: 10.1016/j.jad.2014.09.022.

9. Dennis CL, Faux S, Development and psychometric testing of the breastfeeding self-efficacy scale, Research in Nursing\&Health, 1999; 22, $399-409$.

10. Edhborg M, Friberg M, Lundh W, Widström AM. "Struggling with life": narratives from women with signs of postpartum depression. Scand J Public Health. 2005;33(4):261-7.

11. Özkan H, Üst ZD, Gündoğdu A, Çapık A, Şahin SA, Erken postpartum dönemde emzirme ve depresyon arasındaki ilişki. Şişli Etfal Hastanesi Tip Bülteni. 2014;48(2):124-31.

12. Sipsma HL, Ruiz E, Jones K, Magriples U, Kershaw T. Effect of breastfeeding on postpartum depressive symptoms among adolescent and young adult mothers. J Matern Fetal Neonatal Med. 2017;5:1-6. doi: 10.1080/14767058.2017.1319351. [Epub ahead of print] 
13. Van Doesum KT, Hosman CM, Riksen-Walraven JM, Hoefnagels C. Correlates of depressed mothers' sensitivity toward their infants: the role of maternal, child, and contextual characteristics. J Am Acad Child Adolesc Psychiatry. 2007;46(6):747-56.

14. Karamustafaoğlu N, Tomruk N. Postpartum hüzün ve Depresyonlar. Duygudurum Dizisi. 2000;2:64-71.

15. Blyth R, Creedy DK, Dennis CL, Moyle W, Pratt J, De Vries SM, Effect of maternal confidence on breastfeeding duration: An application of breastfeeding self-efficacy theory. Birth-Issues in Perinatal Care. 2002; 29 4, 278-84.

16. Dennis CL, McQueen K. Does maternal postpartum depressive symptomatology influence infant feeding outcomes? ActaPediatrica. 2007; 96(4): 590-94.

17. Zubaran, C., Foresti K. The correlation between breastfeeding self-efficacy and maternal postpartum depression in southern Brazil Sexual \& Reproductive Healthcare.2013;49-15.

18. Cox JL, Holden JM, Sagousky R. Detection of postnatal depression. Development of the 10-item Edinburgh postnatal depression scale. Br J Psychiatr. 1987;150:782-6.

19. Engindeniz AN, Küey L, Kültür S. Edinburg Doğum Sonrası Depresyon Ölçeği Türkçe Formu geçerlilik ve güvenirlik çalışması, Bahar Sempozyumları. 1997; 1(1):51-52).

20. Dennis CL. The breastfeeding self efficacy scale: psycometric assesment of the short form. Journal of Obstetric, Gynecologic and Neonatal Nursing. 2003; 32(6):734-44.

21. Tokat MA, Okumus H, Dennis CL. Translation and psychometric assessment of the breast-feeding self efficacy scale short form among pregnant and postnatal women in Turkey. Midwifery 2010; 26(1):101-108.

22. Hamdan A, Tamim H. The relationship between postpartum depression and breastfeeding. Int J Psychiatry Med. 2012;43(3):243-259.

23. Hatton, Daniel C. Jane Harrison-Hohner, MSN, Sarah Coste, PhD, Veronica Dorato, RN, Luis B. Curet, MD, and David A. McCarron, MD. Symptoms of Postpartum Depression and Breastfeeding. Journal of Human Lactation, 2015; 21(4): 444-449.

24. Yıldırım GS, Kısa C, Aydemir Ç. Postpartum Depresyon. 3P Dergisi.2004;(ek 4):12-20.

25. Dennis CL. Theoretical underpinnings of breast-feeding confidence: a self-efficacy framework. Journal of Human Lactation. 1999;15(3):195-201.

26. Tokat MA, Okumuş H, Emzirme öz-yeterlilik algısını güçlendirmeye temelli antenatal eğitimin emzirme öz-yeterlilik algısına ve emzirme başarısına etkisi. Hemşirelikte Eğitim ve Araştırma Dergisi. 2013;10(1):219.

27. Forster DA, McLachlan H, Lumley J. Factors associated with breastfeeding at six months postpartum in a group of Australia women. Int Breastfeed J. 2006;18:1-12.

28. Hartmann JM, Mendoza-Sassi RA, Cesar JA. Postpartum depression: prevalence and associated factors. Cad Saude Publica. 2017;9:33(9):e00094016. doi: 10.1590/0102-311X00094016.

29. Nishioka E, Haruna M, Ota E, Matsuzaki M, Murayama R, Yoshimura K, et al. A prospective study of the relationship between breastfeeding and postpartum depressive symptoms appearing at 1-5 months after delivery. J Affect Disord 2011;133:553-9. 